\title{
VIRTUAL TEAMS AND THE ORGANISATIONAL GRAPEVINE
}

RoundRose Associates Ltd, Training \& Development, mdevine@roundrose.com

BELGIUM

Erastos Filos

European Commission, Information Society Technologies, erastos.filos@cec.eu.int

BELGIUM

\begin{abstract}
Virtual teamwork is increasingly becoming a characteristic way of working within and between organisations in the digital economy, bringing both opportunities and drawbacks. This article considers communication in virtual teams and ways in which information and communication technologies (ICTs) can enhance or impede it. It is recognised that the richness of face-to-face communication cannot be captured fully by the tools on offer, although important steps to create team belonging in virtual presence have already been taken. While the tools go some way to permitting distributed team members to interact informally, they cannot go all the way to building and maintaining the personal side of relationships, nor provide stress-relief in many instances. Information overload is highlighted as an example of this failure, and ways to address the problems inherent in ICT-mediated communication and its usage should be sought via inter-disciplinary approaches. On the other hand, the virtual paradigm leads to new organisational forms and organisational culture that tend to strengthen the individual's role in the organisational grapevine.
\end{abstract}

\section{INTRODUCTION}

Global competition is forcing businesses to rethink their work practices in response to demands for shorter time-to-market, enhanced quality and flexible adaptation to varying client requirements. This calls for concurrent work practices (Fan \& Filos, 1999), teamwork and distributed operations. Information and communication technology developments are challenging organisational co-location towards virtual team scenarios that cut across functional, organisational and national boundaries.

A virtual organisation (Camarinha-Matos \& Afsarmanesh, 1999; Filos \& Ouzounis, 2000; Filos \& Banahan, 2000) is a collection of geographically distributed, functionally and/or culturally diverse entities that are linked through ICTs and rely on lateral, dynamic relationships for co-ordination. Despite its diffuse nature, a common identity holds the organisation together in the minds of its constituents. The virtual organisation is managed via teams consisting of physically dispersed employees, forming a "company without walls", a collaborative network of people working together, regardless of location or who "owns" them (DeSanctis 
\& Monge, 1998). A major distinction between virtual and other organisation models (figure 1) consists in that the former are networked - usually via ICTs -, transcending organisational boundaries (Grabowski \& Roberts, 1998), and should be viewed as metaphors of organisation design that is held together, literally, by communication.

\begin{tabular}{|l|l|l|}
\hline \multicolumn{1}{|c|}{ Model } & \multicolumn{1}{|c|}{ Characteristics } & \multicolumn{1}{c|}{ Culture } \\
\hline Corporate, co-located & $\begin{array}{l}\text { Functional units (matrix/hierarchical) and/or } \\
\text { cross-functional teams (networked) }\end{array}$ & Homogeneous \\
\hline Corporate, extended & $\begin{array}{l}\text { Functional units, co-located and/or virtual } \\
\text { teams }\end{array}$ & Homogeneous \\
\hline Virtual organisation & $\begin{array}{l}\text { The organisational 'project': Co-operative } \\
\text { partnerships between organisations enabled } \\
\text { and driven by virtual teams }\end{array}$ & Heterogeneous \\
\hline $\begin{array}{l}\text { Economic web/e-business } \\
\text { community }\end{array}$ & $\begin{array}{l}\text { Organisational network of competencies } \\
\text { ('value network') sustained by virtual teams }\end{array}$ & Heterogeneous \\
\hline
\end{tabular}

Figure 1 - Distinctive elements between co-located and virtual organisation models

A virtual team is defined as a temporary, culturally and/or functionally diverse, geographically dispersed, ICT-mediated communicating work group (Jarvenpaa \& Leidner, 1998). As virtual team work is fast becoming a dominant way of working with many organisations, successful management of virtual teams constitutes a key component to managing virtual organisations. But virtual teams are still made up of individuals with human needs for belonging, communicating and togetherness, an inter-disciplinary approach to virtual team management is required to harness all its benefits and to develop the true potential of this new socio-economic paradigm.

\section{CHANGING COMMUNICATIONS SETTINGS OF VIRTUAL TEAMS}

When individuals are working together towards a common goal, the success of their undertaking depends, to a large extent, on the information exchanged between them which is heavily dependent on the quality of communication between those involved. As communication between human beings involves far more than merely an exchange of information on a rational level, factors such as the emotional atmosphere, the social and cultural context as well as other non-verbal aspects may not be neglected. Contrary to earlier reservations ${ }^{i}$, computer-mediated communication needs not necessarily have a reductionistic impact on team work, but may rather contribute to "revolutionising" its potential (Lipnack \& Stamps, 1997; Devine \& Banahan, 1999).

In the traditional team environment, in which individuals are co-located, communication relies on conventional communication means, that is to say written, or oral forms of inter-personal discourse. While written communication is almost 
exclusively perceived as formal and legally binding, oral communication is differentiated according to the informational settings (formal meetings, or informal social events) in which it is embedded. And since communication between individuals of remote, distributed teams has to rely, almost exclusively, on technology, the distinction between the oral and the written, and with it the distinction between formal and informal discourse, becomes blurred. W. J. Ong therefore speaks of the "secondary orality" (Ong, 1982) in the electronic age. As a result, other distinctive features are likely to become important, such as ease of use, interactivity (which allows the user to feel involved), and even the non-interactivity of asynchronous communication tools.

Face-to-face communication is largely felt to have a distinct advantage over other forms of communication, since this type of interaction involves the full bandwidth of non-verbal behaviour, i.e. facial expressions, voice intonation, movements and postures, physical appearance (Knapp \& Hall, 1992) therefore paying tribute to the higher perception efficiency of non-verbal cues than the actual verbal content (Bradbury, 1995). Individuals need non-explicit communication to infer a meaning and gauge a feeling or a mood, the "true" intention of their interlocutor. Face-to-face interaction also permits instantaneous feedback of how well a message has been understood, thus reducing the grounds for miscommunication. The essence of good communication therefore is a measure of how well one has been understood, rather than how well one has expressed something verbally.

Communication via ICT tools foregoes the ability to use non-verbal behaviour as a resource in communication. On the other hand, given the fact that much of nonverbal behaviour is culture-specific (Miell \& Dallos, 1996) the absence of these cues can also mean that room for possible miscommunication is reduced.

\section{INFORMAL COMMUNICATION}

There is another feature, beyond the immediacy and togetherness inherent in the traditional paradigm, which in the past has tended to be underestimated, but now seems to be increasingly recognised due to its importance for leveraging the knowledge of individuals within a team or an organisation; i.e. the tacit knowledge dimension (Polanyi, 1966; Senker, 1993). The route to its access being informal communication.

When a group of colleagues sits down to lunch in the canteen, one can be sure that at least half of their time will be spent discussing work issues. These colleagues will invariably discuss their own personal ideas, explore "what-if" scenarios and exchange visions of the future. The informal setting is a "safe" environment for the expression of ideas and encourages the exchange of more daring or atypical perspectives. It encourages a degree of openness uncharacteristic of a formal meeting. The creativity that comes from exploring synergy is enhanced, mutual understanding and respect between participants is increased, and the bond between them strengthened.

The "coffee chat" amongst work colleagues not only serves as a social forum for individuals working in an organisation, but is an essential component of the organisational grapevine and, as such, provides an important channel through which 
information is exchanged and problems are shared. Three elements of informal communication settings deserve consideration.

First, informal communication contributes to informational added value and improved contextual understanding. Information exchanged informally may or may not have direct relevance to the tasks or projects of all those taking part. Information gleaned may, however, contribute to everyone's understanding of the overall context within which his particular tasks are being carried out. In essence, the information provides the individual with a wider context, hence its added value.

Second, informal communication can stimulate individuals' creativity. Seemingly unimportant items of information may contribute to an enhanced understanding of a technical issue and may provide new creative input to a task in which the individual, or a colleague, may be involved. Much information which is exchanged informally, and is often referred to disparagingly as "gossip", (and therefore too trivial to be written in a report, or reported at a formal meeting), may nevertheless prove crucial to the resolution of a problem or clarification of a task. To illustrate, "Mrs Jones from Accounts is off on maternity leave", may give Mr Smith a clear picture as to why the accounts for his department are so late this month. Armed with this information, which he has received through the organisational grapevine, Mr. Smith now understands the situation more clearly, and is therefore in a better position to act. Information which may appear trivial to one person can be of crucial importance to another. The issue with this type of information is that outside this "social" forum, it is difficult to get hold of. It rarely comes through more formal channels such as meetings and project reports.

Third, the improved organisational cohesion and the stress-relieving effects of discussion in non-threatening informal settings. In addition to the two elements mentioned above, informal communication also bears the potential to generate a sense of belonging (Nonaka \& Takeuchi, 1995) for particular individuals, an important team motivating factor. Communicating informally allows individuals to get acquainted with one another on a personal level, enabling them to explore how others think, what interests others may have and how others like doing things. Informal communication also provides individuals with a powerful means of gaining feedback about themselves, the way they are perceived, and their overall performance. In the virtual scenario, especially where team players work across organisational boundaries, this type of feedback may be lacking. More formal methods of feedback (e.g. mentoring, coaching) are always possible, though they are difficult to organise and tend to be more formal. The lack of a forum in which individuals can air difficulties, can provoke a feeling of isolation and lack of direction, and consequently increase stress and loneliness, lowering effectiveness (Allen et al., 1982). Informal settings provide a way of alleviating these effects in a non-threatening and motivating way. As the saying goes, "a problem shared is a problem halved", and discussion with others provides new perspectives through which new solutions may arise.

\section{VIRTUAL TEAM COMMUNICATION}

Direct interactive communication tools facilitate "virtual presence" via a large number of internet-based conferencing tools as illustrated in figure 2. Interactive 
collaborative working of virtual teams has been greatly improved through the introduction of whiteboard techniques, which offer visualisation possibilities to remote conferencing participants, the concurrent access to text and graphical documents and possibilities to legalise them, e.g. digital signatures.

Direct non-interactive communication tools, like fax, voice- and e-mail, help "preserve distance" between communicating partners, by allowing recipients of the communicated message to respond in their own time.

With many internet-based collaborative work tools, communication between virtual team members ceases to be direct, i.e. point-to-point. Distributed teams are increasingly working remotely and asynchronously in shared knowledge data environments. While applications that enable access to remotely located and distributed databases of collaborating business partners are increasingly becoming available, often simple file servers prove sufficient in enabling concurrent working on shared information bases, provided partners use the same application tools. "Shared workspace" systems which support distributed team activities such as document upload, event notification and group management are becoming more widely available (Bentley et al., 1997). To access such systems, normally only a standard web browser is needed.

\begin{tabular}{|c|c|c|c|c|}
\hline $\begin{array}{l}\text { Communi- } \\
\text { cation } \\
\text { types }\end{array}$ & $\begin{array}{l}\text { Technology } \\
\text { tools }\end{array}$ & $\begin{array}{l}\text { Informal } \\
\text { commu- } \\
\text { nication }\end{array}$ & Contribution to teaming & $\begin{array}{l}\text { Limitations for } \\
\text { teaming }\end{array}$ \\
\hline $\begin{array}{l}\text { Face-to- } \\
\text { face }\end{array}$ & & $\begin{array}{l}\text { Very } \\
\text { high }\end{array}$ & $\begin{array}{l}\text { - Immediacy } \\
\text { - Feedback } \\
\text { - Full spectrum of non- } \\
\text { verbal communication } \\
\text { elements } \\
\end{array}$ & $\begin{array}{l}\text { Some non-verbal } \\
\text { aspects may impede } \\
\text { teaming }\end{array}$ \\
\hline $\begin{array}{l}\text { Direct, } \\
\text { interactive }\end{array}$ & $\begin{array}{l}\text { - Telephone } \\
\text { conferencing } \\
\text { - Computer } \\
\text { conferencing } \\
\text { - Video } \\
\text { conferencing } \\
\end{array}$ & High & $\begin{array}{l}\text { - Immediacy } \\
\text { - Feedback } \\
\text { - Non-verbal } \\
\text { communication elements }\end{array}$ & $\begin{array}{l}\text { Reduced non-verbal } \\
\text { communications } \\
\text { spectrum: limited to } \\
\text { audible \& to } \\
\text { 'camera perspective' } \\
\text { visual }\end{array}$ \\
\hline $\begin{array}{l}\text { Direct, } \\
\text { non- } \\
\text { interactive }\end{array}$ & $\begin{array}{l}\text { - Fax } \\
\text { - Voice-mail } \\
\text { - E-mail }\end{array}$ & High & $\begin{array}{l}\text { - Facilitates asynchronous } \\
\text { working } \\
\text { - Non-immediacy may } \\
\text { contribute to stress relief } \\
\text { - Ease of use may prompt } \\
\text { (informal) openness } \\
\text { amongst team members } \\
\text { - Information 'push' } \\
\end{array}$ & $\begin{array}{l}\text { - Non-immediacy } \\
\text { - Delayed feedback }\end{array}$ \\
\hline Indirect & $\begin{array}{l}\text { - Collaborative } \\
\text { platforms } \\
\text { - Document } \\
\text { servers } \\
\text { - Electronic } \\
\text { commerce } \\
\text { applications }\end{array}$ & Very low & $\begin{array}{l}\text { - Speed \& efficiency } \\
\text { - Transparency ('who does } \\
\text { what \& how') } \\
\text { - Data consistency/ } \\
\text { configuration control: } \\
\text { common information base } \\
\text { for all } \\
\text { - Information 'pull' }\end{array}$ & $\begin{array}{l}\text { - Impersonal } \\
\text { working } \\
\text { - Team members } \\
\text { are controllable } \\
\text { - Interfacing } \\
\text { difficulties due to } \\
\text { heterogeneous IT } \\
\text { environments }\end{array}$ \\
\hline
\end{tabular}

Figure 2 - Communication types. Their impact on teaming and on informal communication 
However, problems still remain for organisationally heterogeneous teams working on different IT platforms, due to an incompatibility of data of proprietary applications. However, standardisation efforts in STEP, CORBA and XML may help solve these interoperability problems soon.

\section{DO VIRTUAL TEAMS MISS THE "COFFEE CHAT"?}

At first glance the virtual team appears to lack many of the characteristics which support the development of an effective team, because by definition, it is embedded in a mediated environment in which communication processes are heavily dependent on technology. This may give rise to feelings of isolation and remoteness, but they can be overcome, firstly by providing ways to achieve a balance between virtual and face-to-face communication on an occasional basis, and secondly, by sustaining informal communication amongst virtual team members.

Virtual organisations are dependent on informal communication (Ahuja \& Carley, 1998), as formal rules, procedures, clear reporting relationships, and norms are not established. But the rate of exchange of social information is much slower with virtual teams. On the other hand, teams that exchange information about their motivations, habits, and goals rate themselves higher on trustworthiness (Jarvenpaa \& Shaw, 1998).

\begin{tabular}{|l|l|l|}
\hline Team Culture Issues & \multicolumn{1}{|c|}{ Traditional teams } & \multicolumn{1}{c|}{ Virtual teams } \\
\hline $\begin{array}{l}\text { Collaborative } \\
\text { attitude }\end{array}$ & Respectful & Trusting \\
\hline Degree of empathy & Low & High \\
\hline $\begin{array}{l}\text { Attitude towards } \\
\text { power and authority }\end{array}$ & $\begin{array}{l}\text { Adherence to rules; following implicit } \\
\text { conventions }\end{array}$ & Tendency to be anarchic \\
\hline $\begin{array}{l}\text { Informational } \\
\text { interface }\end{array}$ & $\begin{array}{l}\text { Not explicitly specified; less rules, as } \\
\text { communication is mostly face-to-face }\end{array}$ & $\begin{array}{l}\text { Needs to be specified carefully } \\
\text { (document templates etc.) }\end{array}$ \\
\hline Communication style & $\begin{array}{l}\text { Ambiguous; non-explicit (relying on } \\
\text { richness of face-to-face communication) }\end{array}$ & $\begin{array}{l}\text { Low degree of ambiguity; } \\
\text { explicit }\end{array}$ \\
\hline Rules and procedures & $\begin{array}{l}\text { High degree of formal communication, } \\
\text { as rules and conventions are given by } \\
\text { the organisational context }\end{array}$ & $\begin{array}{l}\text { High degree of informal } \\
\text { communication as rules and } \\
\text { conventions need to be } \\
\text { established; difficult consensus } \\
\text { formation }\end{array}$ \\
\hline Quality of work & Lax attitude to details & $\begin{array}{l}\text { Quality of virtual collaboration } \\
\text { depends on high quality of } \\
\text { informational interface }\end{array}$ \\
\hline
\end{tabular}

Figure 3- Team culture. Distinctive elements between co-located and virtual teams 
There are ways in which a creative, informal communications environment within virtual teams can be achieved. One possibility is offered by the Swedish

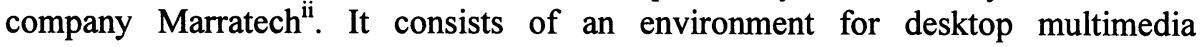
conferencing over the internet. Here, traditional video/audio tools are enhanced by a series of Java-enabled tools, such as whiteboarding, synchronised changing and viewing of web pages, on-line voting for teams, presentation authoring and mediaon-demand. The multi-party communication tool known as "the electronic corridor", provides an interesting solution. Users can meet spontaneously to discuss matters of mutual interest, but also overhear other conversations, an environment mirroring the physical corridor setting. The screen displays a column of small images of the project members' offices, no matter what part of the world they are in. Each can see what the others are doing and interact at any time. This creates a feeling of presence, albeit a virtual presence. You don't have to go for coffee in order to chat with your colleagues. Without leaving your office you can spontaneously begin a conversation with anyone in your electronic corridor. If you want to see a project member in full screen format, you just have to zoom in on him or her. The possibility is there to turn your camera off, but experience shows that everyone leaves it on ${ }^{\text {iii }}$.

As possibilities expand for effective and efficient communication within virtual teams, the tools described above go a long way towards simulating real presence in a virtual scenario. However, it should not be forgotten that ICT-mediated communication will never become a real substitute for face-to-face communication, despite all the "better-than-being-there" scenarios (Benjamin, 1998). Remote team working may bring isolation but may also permit work to a degree of intimacy hitherto unknown. In a virtual context individuals are likely to be more open, i.e. to say things they would perhaps be reluctant to say face-to-face, a basic presupposition for enhancing knowledge sharing and trust building and may be considered as one of the important advantages of virtual teams in comparison with traditional teams (figure 3 ).

\section{INFORMATION OVERLOAD}

If there is a downside to connectivity, it is information overload. The virtual context can make people vulnerable to access more information than they can digest. It can become a threatening drawback for the efficiency of virtual teams.

M. Weiser and J. S. Brown (Weiser \& Brown, 1998) use human optical vision as an analogy to explain information overload and show possibilities to avoid it. They believe that the right balance between technology, design and an understanding of work processes can greatly reduce the distortion created by a disproportionate demand on the centre of human attention vs. the low-attention periphery. They identify ten biases through which ICT contributes to this unbalance,

(1) It transmits explicit information to the neglect of "implied" messages;

(2) It "homogenises", flattens and reduces to monotone levels of importance inherent in informational content, thereby contributing to miscommunication;

(3) It tends to "strip out" content from its context, thereby contributing to a loss of meaning;

(4) It alters the human conceptualisation of information by "reframing" content stripped of its original context into a new context; 
(5) It overloads one part of the brain, by leaving important sources of intelligence untapped ("monosensing");

(6) It tends to interrupt focus and the mental processes by requiring mental energy to create a flow of snapshots;

(7) The homogenising, stripping and reframing tends to distort the genre-specific peripheral cues of informational contexts;

(8) Interactive, multimedia design is still in its infancy, leaving most digital design awkward and clumsy. The result - "uglying" - is most often caused by ignoring the periphery;

(9) "Reifying" reduces and restricts human range of activities to only those that have been digitised or are digitisable;

(10) All biases together create a destabilising effect leaving users upset, frustrated, and exhausted.

ICTs through their ubiquitous and voluminous provision of information, must engage a richer periphery. Trying to catch up with an increasing "volume of bits" users will be helplessly overwhelmed. The tools developed and used need to engage the periphery as well as the centre. A balanced view must continuously be sought.

\section{ORGANISATIONAL IMPLICATIONS}

The very technologies that offer individuals the freedom to work any time and anywhere may also fray the ties that bind organisation members to each other and to their employer. In particular, the cues that pull team members together in traditional organisational settings include dress codes, shared language, shared organisational culture - e.g. routines and structures -, office buildings, and co-location. Consequently, as these factors are less readily available and less indicative of meaning in the virtual context, the links between virtual team members may be less tangible and more social and psychological in nature. A recent study on the effects of different communication media on the organisational identification of virtual workers revealed that "electronic media" are particularly important for the maintenance of organisational identification, since the frequency of their usage seems to correlate strongly with it, whereas face-to-face contact may be more critical in creating it (Wiesenfeld et al., 1998). Research focused on new organisational forms needs to consider both the "system of work" and the "system of meaning", the institutional facets of the organisation, specifically the values attached to the work engaged in (Scott, 1991). Organisational identification is a part of the larger construct that has to do with the creation and preservation of the "system of meaning" in these new emerging work forms.

Another challenge for the distributed team is the difficulty to co-ordinate and to manage it (Devine \& Banahan, 1999), especially if the cohesion of the virtual team may suffer, from a lack of immediacy in team members' interactions, from a diversity in organisational culture - e.g. diverging business interests, unclear perceptions regarding the handling of intellectual property -, from a divergence of expertise levels, as well as linguistic and socio-cultural heterogeneity.

The managerial dilemma comes down to the question, "How do you manage people whom you do not see?" Virtual teams have to be run on trust rather than on control (Handy, 1995) . Research results (Jarvenpaa \& Leidner, 1998) suggest that 
in cross-cultural virtual teams, trust might take on a form of swift trust based on clear role divisions among members who have well defined specialities, i.e. imported and maintained through ICT-mediated communication. Developing trust in virtual organisations requires constant, continual communication among members to build relationships that provide the foundation for trust. ICT-mediated interactions and communications are important to the development of trust, as they offer a platform for informal and open sharing of thoughts, expectations, assumptions and values, but also the opportunity to form alliances of collective responsibilities rather than hierarchies of reporting relationships with the parent organisation as they provide clarification, sense making, organisational growth, and opportunities for individuals to discuss improvements to their organisation. Thus, high levels of trust can contribute to strengthen linkages among member organisations (Grabowski \& Roberts, 1998).

\begin{tabular}{|l|l|l|}
\hline Organisation Issues & \multicolumn{1}{|c|}{ Traditional teams } & \multicolumn{1}{|c|}{ Virtual teams } \\
\hline Organisational culture & Predominantly homogeneous & $\begin{array}{l}\text { Homogeneous or } \\
\text { heterogeneous; dynamic }\end{array}$ \\
\hline Communication & $\begin{array}{l}\text { Predominantly face-to-face; vertical; } \\
\text { difficult consensus formation in } \\
\text { culturally/functionally diverse teams }\end{array}$ & $\begin{array}{l}\text { Predominantly mediated; } \\
\text { lateral; easier spanning } \\
\text { across cultural/functional } \\
\text { boundaries }\end{array}$ \\
\hline Working & $\begin{array}{l}\text { - Synchronous working (i.e. limited to } \\
\text { office hours) } \\
\text { Collaboration with co-located } \\
\text { individuals }\end{array}$ & $\begin{array}{l}\text { - Asynchronous (i.e. } \\
\text { 24-hours) working } \\
\text { possible } \\
\text { Collaboration with } \\
\text { remotely working } \\
\text { individuals }\end{array}$ \\
\hline Leadership/authority & $\begin{array}{l}\text { Hierarchical (top-down); concentrated } \\
\text { on persons; fixed (i.e. via assigned } \\
\text { roles) }\end{array}$ & $\begin{array}{l}\text { Networked (autonomous } \\
\text { nodes); distributed (i.e. } \\
\text { competencies-based); } \\
\text { rotating (shared } \\
\text { responsibilities); }\end{array}$ \\
\hline Performance management & Control-based & \begin{tabular}{l} 
Trust-based (goodwill) \\
\hline
\end{tabular} \\
\hline
\end{tabular}

Figure 4 - Team organisation. Distinctive elements between co-located and virtual teams

Distributed teams enjoy the freedom to define for themselves those management and task assignment schemes that best suit their specific situation. Indeed, each team can build its own project culture, which can be tailored to its individual needs and goals, and may be less bureaucratic than the cultures of the different organisations partaking. Since the virtual context requires lateral communication and active involvement from each individual team member, it undeniably tends to lead to flat organisational structures, participatory management practices, and novel schemes of shared responsibility, e.g. management tasks performed in rotation etc., see figure 
4). Research indeed suggests that virtual organisations tend to be non-hierarchical and decentralised, better able to handle tasks that are non-routine and demand flexibility and adaptability (Ahuja \& Carley, 1998).

The traditional focus on the team leader's role is prone to downgrade the position of the other team members. In that context, the most senior, most experienced, member is appointed team leader. This hierarchical management scheme, as well as the assumption that teams require a single leader, is called into question, because virtual teams benefit from having different types of leaders performing complementary tasks, depending on project stage. Each member of the team is empowered and responsibility is shared. But, in self-managing virtual teams where there is no one person or institution to which all team members are accountable, penalties would also have to be imposed by the team members themselves (Jarvenpaa \& Shaw, 1998).

\section{CONCLUSIONS}

Virtual organisations and in particular virtual teams are dependent on ICTs and the quality of communication that these can sustain. The necessity of informal communication for the individuals' perception of the context of their distributed work environment, as well as the importance of social information for creativity stimulus and stress relief were highlighted. While the richness of face-to-face communication cannot be captured fully by the ICT tools on offer, although important steps to create team belonging in virtual presence have been taken, they go some way to permitting distributed team members to interact also informally. Information overload is highlighted as an example of the problems inherent in ICTmediated communication and its usage. On the other hand, the virtual paradigm is seen to lead to new organisational forms and organisational culture that tend to strengthen the individual's role in the organisational grapevine. As the ICT offers become more user-oriented, inter-disciplinary research is needed to better understand informal communication patterns in distributed teams as they relate to technology and with regard to their impact on virtual organisation management.

\section{ACKNOWLEDGEMENTS}

The views expressed in this article are those of the authors only. They resulted from a common follow-up activity of cross-organisational collaborative R\&D projects supported by the European Commission's IT research programme "Esprit".

\section{REFERENCES}

1. Ahuja MK, Carley KM. Network Structure in Virtual Organisations. Journal of Computermediated Communication; 3 (4) 1998. On-line: http://jcmc.huji.ac.il/vol3/issue4/ahuja.html.

2. Allen RD, Hitt MT, Greer CR. Occupational Stress and Perceived Organizational Effectiveness in Formal Groups: An Examination of Stress Level and Stress Type. Personnel Psychology. Summer 1982, 263-269.

3. Benjamin R. Cybercommunities. Better than Being There? In: Tapscott et al., 1998, 298-316. 
4. Bentley R, Appelt W, Busbach U, Hinrichs E, Kerr D, Sikkel S, Trevor J, Woetzel G. Basic Support for Cooperative Work on the World Wide Web, in: International Journal of Human-Computer Studies 46(6)1997: Special issue on Innovative Applications of the World Wide Web, 827-846.

5. Bradbury A. Successful Presentation Skills, Kogan Page, 1995.

6. Camarinha-Matos LM, Afsarmanesh H, eds. Infrastructures for Virtual Enterprises. Networking Industrial Enterprises. IFIP TC5 WG5.3 / PRODNET Working Conference for Virtual Enterprises (PROVE'99), Porto, Portugal, 27-28 October 1999, Boston: Kluwer Academic Publishers.

7. DeSanctis G, Monge P. Communication Processes for Virtual Organisations. Journal of Computermediated Communication, 3 (4) 1998. On-line: http://jcmc.huji.ac.il/vol3/issue4/desanctis.html.

8. Devine M, Banahan E. The Virtual Project. Managing Teams in Distributed Environments. Proceedings of ICE'99, International Conference on Concurrent Enterprising. The Hague, 15-17 March 1999, 425-431.

9. Fan I-S, Filos E. Concurrent Engineering: Esprit-supported R\&D Projects in a World-wide Context, Proceedings of ICE'99, International Conference on Concurrent Enterprising. The Hague, 15-17 March 1999, 177-189.

10. Filos E, Ouzounis VK. Virtual Organisations. Technologies, Trends, Standards and the Contribution of the European RTD Programmes. International Journal of Computer Applications in Technology. Special Issue: "Applications in Industry of Product and Process Modelling Using Standards", 2000, forthcoming.

11. Filos E, Banahan E. Towards the Smart Organisation. An Emerging Organisational Paradigm and the Contribution of the European RTD Programmes. Journal of Intelligent Manufacturing Systems. Special Issue: "Virtual Organisations", 2000, forthcoming.

12. Grabowski M, Roberts KH. Risk Mitigation in Virtual Organisations. Journal of Computermediated Communication, 3 (4) 1998. On-line: http://jcmc.huji.ac.il/vol3/issue4/grabowski.html.

13. Handy C. Trust and the Virtual Organisation. Harvard Business Review; May-June, 1995, 25-50.

14. Jarvenpaa SL, Leidner DE. Communication and Trust in Global Virtual Teams, Journal of

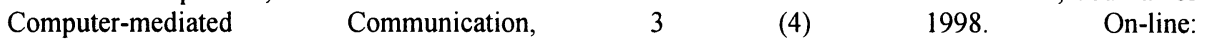
http://jcmc.huji.ac.il/vol3/issue4/jarvenpaa.html.

15. Jarvenpaa SL, Shaw TR. Global Virtual Teams: Integrating Models of Trust. Proceedings VONet Workshop, 27-28 April 1998, 35-51.

16. Knapp ML and Hall JA. Nonverbal Communication in Human Interaction. Third Edition. Fort Worth: Harcourt Brace Jovanovich, 1992.

17. Lipnack J, Stamps J. Virtual Teams. Reaching across Space, Time, and Organizations with Technology. New York: John Wiley \& Sons, 1997.

18. Miell D, Dallos R. Social Interaction and Personal Relationships. The Open University, 1996. 1995.

19. Nonaka I, Takeuchi H. The Knowledge-Creating Company. New York: Oxford University Press,

20. Ong, WJ. Orality and Literacy. The Technologising of the Word, London: Methuen, 1982.

21. Polanyi M. The Tacit Dimension. London: Routledge \& Kegan Paul, 1966.

22. Scott WR. Unpacking Institutional Arguments. In: Powell WW, DiMaggio PJ, eds. The New Institutionalism in Organisational Analysis, Chicago: University of Chicago Press, 1991, 164-182; cit. Wiesenfeldt BM et al.

23. Senker J. The Contribution of Tacit Knowledge to Innovation. Artificial Intelligence \& Society 7 (1993), 208-224.

24. Slouka M. War of the Worlds: Cyberspace and the High-Tech Assault on Reality, New York: Basic Books, 1995.

25. Soete L, ed. Building the European Information Society for Us All. First Reflections of the High Level Group of Experts, Interim Report, European Commission, Directorate General V, Brussels, 1996.

26. Stoll C. Silicon Snake Oil: Second Thoughts on the Information Superhighway, New York: Doubleday, 1995.

27. Tapscott D, Lowy A, Ticoll D, eds. Blueprint to the Digital Economy. Creating Wealth in the Era of E-Business, New York: McGraw Hill, 1998.

28. Weiser M, Brown JS. Center and Periphery. Balancing the Bias of Digital Technology. In: Tapscott et al., 1998, 317-335.

29. Wiesenfeld BM, Raghuram S, Garud R. Communication Patterns as Determinants of Organizational Identification in A Virtual Organization. Journal of Computer-mediated Communication, 3 (4) 1998. On-line: http://jcmc.huji.ac.il/vol3/issue4/wiesenfeld.html. 
On simulated reality (Slouka, 1995, p. 7); on reduced human contact and informational stress (Soete, 1996, pp. 36-37); the Information Highway as "impoverished community" (Stoll, 1995, p. 47)

ii A spin-off from the Technical University of Lulea in northern Sweden, http://www.marratech.com

iii The toolset called "Marratech Pro" (mStar) was developed at the Centre for Distance-spanning Technologies (http://www.cdt.luth.se). Project MATES was funded under the European Commission's R\&D programme "Esprit" 